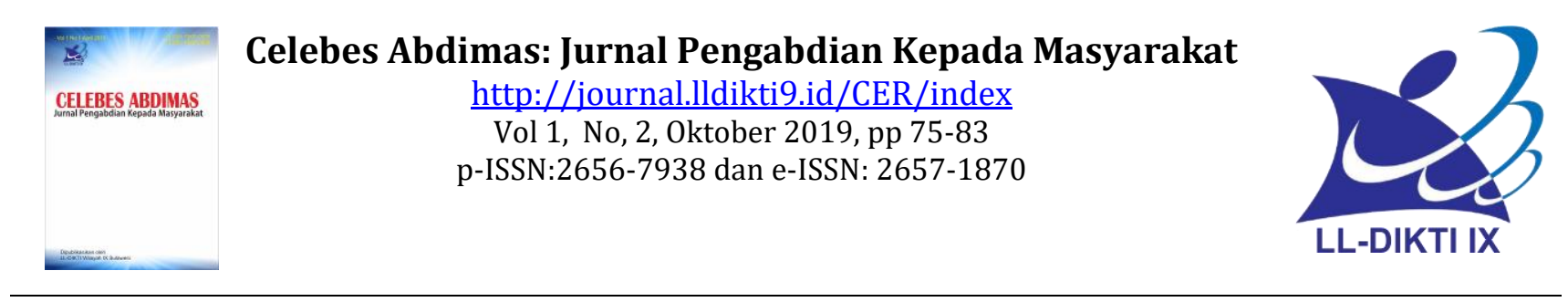

\title{
Iptek Bagi Pendidikan T.K. Pkk Paropo, Kelurahan Paropo, Kecamatan Panakukkang, Kota Makassar
}

\author{
Andi Sugiati ${ }^{1}$, Intisari' ${ }^{2}$, Muhajir ${ }^{3}$, Rismawati ${ }^{4}$ \\ ${ }_{1}^{1}$ Ilmu Hukum, Universitas Muhammadiyah Makassar \\ Email: a.sugiati07@gmail.com \\ 2 Pendidikan Anak Usia Dini (PAUD), Universitas Muhammadiyah Makassar \\ ${ }^{3}$ Pendidikan Pancasila Dan Kewarganegaraan (PPKn), Universitas Muhammadiyah Makassar \\ ${ }^{4}$ Pendidikan Pancasila Dan Kewarganegaraan (PPKn), Universitas Muhammadiyah Makassar
}

\section{Artikel info}

Artikel history:

Received;September-2019

Revised: September-2019

Accepted;Oktober-2019

Publish: Oktober-2019
Abstract. Early childhood education (PAUD) is the main basis in the personal development of children, both character, physical abilities, cognitive, language, art, social, emotional, spiritual, selfdiscipline, self-concept, and independence. Therefore, in providing educational services, it is necessary to understand the characteristics of growth and the way children learn. Kindergarten (T.K) Paropo needs to be managed well in order to provide optimal services in accordance with the characteristics and growth. The purpose of implementing this program is to provide additional knowledge and understanding to teachers about the management of education management and teaching methods. The method used is mentoring or management training and teaching methods. Things done to achieve these objectives are through development models, namely (1) Situation Analysis, (2) Formulation of Problems, (3) Hypotheses for Action, (4) Action Planning, (5) Implementation of Actions and monitoring, (6) Evaluation and (7) Reflections for further development. After this training, it is hoped that teachers in PKK Paropo Kindergarten can implement it, so as to create a learning atmosphere that is more attractive to students.

Abstract. Pendidikan anak usia dini (PAUD) merupakan peletak dasar pertama dan utama dalam pengembangan pribadi anak, baik berkaitan denga karakter, kemapuan fisik, kognetif, bahasa, seni, sosial, emosional, spritual, disiplin diri, konsep diri, maupun kemandirian. Oleh karena itu, dalam memberikan layanan pendidikan, perlu di fahami karakteristik perkembangan serta cara-cara anak belajar. Taman Kanak-Kanak (T.K) Paropo perlu dikelolah dengan baik agar bisa memberikan layanan yang optimal sesuai dengan karakteristik dan perkembangannya. Tujuan dari pelaksanaan program ini adalah memberikan tambahan pengetahuan dan pemahaman kepada guru tentang pengelolaan manajemen pendidikan dan metode pengajaran. metode yang di lakukan adalah melalui pendampingan atau pelatihan manajemen dan metode pengajaran Pendekatan yang ditawarkan untuk mencapai tujuan tersebut adalah melalui model 
pengembangan (1) Analisis Situasi, (2) Perumuan Masalah, (3) Hipotesis Tindakan, (4) Perencanaan Tindakan, (5) Inplementasi Tindakan dan memonitoring, (6) Evaluasi dan (7) Refleksi untuk pengembangan selanjutnya. setelah pelatihan ini, diharapkan guru-guru yang ada di TK PKK Paropo bisa menerapkannya agar menciptakan suasana belajar yang lebih menarik minat peserta didik, dan anak tidak salah konsep dalam pembelajaran.

Keywords: Iptek; T.K;

Pendampingan;

Pelatihan; (5).
Coresponden author:

Alamat : Jl. Abdullah Daeng Sirua, Btn. Paropo Indah, Blok K4, Kecamatan Panakukkang, Keluarahan Paropo, Kota Makassar Email: a.sugiati07@gmail.com

artikel dengan akses terbuka dibawah lisensi CC BY -4.0

\section{PENDAHULUAN}

Pendidikan anak usia dini (PAUD) merupakan peletak dasar pertama dan utama dalam pengembangan pribadi anak, baik berkaitan denga karakter, kemapuan fisik, kognetif, bahasa, seni, sosial, emosional, spritual, disiplin diri, konsep diri, maupun kemandirian. Oleh karena itu, dalam memberikan layanan pendidikan, perlu di fahami karakteristik perkembangan serta caracara anak belajar.

Taman Kanak-kanak (T.K), kampung Paropo berdiri sejak tahun 1986, yang diprakarsai oleh masyarakat kampung Paropo, yaitu ibu-ibu anggota PKK (Pemberdayaan Kesejahteraan Keluarga dan masyarakat yang ada dikampung Paropo), dan pemerintahan setempat untuk mewadahi anak-anak usia dini yang ingin bersekolah yang ada di kampung tersebut, dengan prakarsaa tersebut maka T.K.Kampung Paropo di beri nama T.K. PKK Paropo..

Kondisi Sekolah Taman Kanak-kanak kampong Paropo (T.K. PKK Paropo), menempati gedung milik salah satu warga kampung tersebut, yang dengan secara sukarela memberikan untuk ditempati sementara dalam menunjang proses pembelajaran. T.K Paropo tidak sama seperti kondisi T.K yang ada di T.K. lainnya, sebab perhatian pemerintah juga berpengaruh terhadap perkembangan sekolah T.K. Keberadaan T.K. Pembina yang ada di tingkat Provinsi dan Kota belum dapat menjadi contoh. Oleh karena itu banyak T.K Swasta yang mendominasi di Kelurahan Paropo, Taman Kanak-kanak Kampung Paropo (T.K. PKK Paropo), juga menjadi bagian dari tanggung jawab Direktorat Pembinaan Pendidikan Anak Usia Dini (PAUD)

Jumlah murid yang ada di TK PKK Paropo adalah sebanyak:

\begin{tabular}{ll}
\hline Murid TK PKK Paropo & Jumlah \\
\hline Laki-laki & 9 orang \\
Perempuan & 8 orang \\
\hline
\end{tabular}


Jumlah Guru/tenaga pengajara adalah:

\begin{tabular}{|c|c|c|}
\hline $\begin{array}{l}\text { Jumlah } \\
\text { Pengajar }\end{array}$ & Gur/Tenaga Jenis Kelamin & Jabatan \\
\hline 1 orang & Perempuan & Kepala Sekolah \\
\hline 2 orang & Perempuan & Guru dan Tenaga Pengajar \\
\hline
\end{tabular}

Sumber data TK PKK Paropo

Di T.K PKK Paropo, tidak sama dengan Sekolah T.K lainnya yang dilengkapi dengan sarana dan prasarana yang mamadai yang menunjang proses belajar dan mengajar. Di T.K.PKK Paropo memiliki ruang kelas akan tetapi tidak memiliki ruang untuk bermain, demikian pula dalam pengelolaan manajemennya, tidak terkelolah dengan baik, masih perlu pengembangan dari segi manajemen dan metode pembelajaran guna menunjang kualitas pembelajaran pada T.K tersebut.

Permasalahan yang ditemukan di lapangan berdasarkan observasi yang dilakukan adalah, masih kurang pengelolaan manajemen seperti administrasi dan pembukuan, serta organisasi dan manajemen pembelajarannya, bahan ajar yang belum baik, dan metode pembelajaran yang diberikan guru, sehingga masih banyak anak yang tidak berkonsentrasi penuh terhadap pembelajaran yang diberikan guru, dikarenakan metode pembelajaran yang diberikan guru kurang menarik minat anak untuk memperhatikan pembelajaran, guru lebih banyak yang berperan aktif, kurang dalam pengembangan kreativitas dan proses-proses intelektual lainnya, misalnya memberikan karya nyata, eksprimen dan lain sebagainya. Ini yang kurang dilakukan sehingga cepat menimbulkan rasa jenuh atau bosan dalam belajar, padahal melalui suatu karya nyata, setiap anak akan menggunakan imajinasinya untuk membentuk suatu bangunan atau benda tertentu sesuai dengan khayalannya.

Dalam menciptakan karya nyata bukan hanya kreativitas yang akan berkembang dengan baik, tetapi juga kemampuan kognetif anak. Strategi ini akan mendorong anak menggunakan imajinasinya untuk mencoba sesuatu yang baru bagi dirinya baik berupa benda atau bangunan tertentu. Ketika anak menciptakan suatu karya nyata terjadi proses internalisasi antara imajinasi dan kemampuan kreatifnya. Karya nyata anak dapat berupa sesuatu yang baru bagi dirinya atau merupakan inovasi dari karya-karya yang sudah ada, dan setiap anak akan menunjukkan bentuk karya yang berbeda-beda sesuai dengan kemapuan dan daya imajinasinya. Strategi pengembangan kreativitas melalui suatu karya nyata ini memberikan kesempatan pada setiap anak untuk menciptakan benda buatan sendiri yang belum pernah ditemuinya. Mereka juga bisa memodifikasi sesuatu dari benda yang telah ada sebelumnya. Oleh karena itu diperlukan upaya yang mampu menfasilitasi anak dalam masa tumbuh kembangnya berupa kegiatan pendidikan dan pembelajaran sesuai dengan usia, kebutuhan dan minat anak, sebab saat paling baik seorang anak untuk memperoleh pendidikan yang tepat adalah pada usia dini, sebab anak pada masa ini biasa meniru atau mengikuti nilai perilaku yang ada di sekitarnya. Lingkungan keluarga maupun lingkungan sekitarnya. Penanaman pendidikan perlu diberikan sejak usia dini, karena di usia inilah anak memasuki masa keemasan (golden age) yang hanya terjadi sekali dalam hidupnya. Usia dini merupakan masa yang sangat penting untuk mengembangkan kecerdasan anak. Pentingnya pendidikan pada anak usia dini, diharapkan agar terbentuk manusia yang cerdas. PAUD merupakan basis pembentukan karakter manusia, sehingga terbentuk perilaku dan kemampuan dasar sesuai dengan tahap perkembangannya agar selanjutnya dapat menjadi warga negara yang baik sesuai harapan. Pendidikan Anak Usia Dini (PAUD), bertujuan adalah mengembangkan berbagai potensi anak sejak dini sebagai persiapan untuk hidup dan dapat menyesuaikan diri dengan lingkungannya.

Solusi yang ditawarkan pada permasalahan tersebut yaitu Melakukan Pendampingan dan pelatihan manajemen pengelolaan administrasi Pendidikan, dan Memberikan pelatihan bagaimana mendesain metode/media pembelajaran yang sesuai dengan karakteristik anak usia 
78| Celebes Abdimas: Jurnal Pengabdian Kepada Masyarakat

Taman Kanak-kanak yaitu antara lain, bermain sambil belajar, karyawisata, bercerita, demonstrasi, proyek dan pemberian tugas.

Melihat hal tersebut melalui Pendikan T.K. ini diharapkan semua pihak dapat mendukung upaya mewujudkan T.K yang dapat meningkatkan potensi dan kemampuan anak bangsa yang cerdas dan kreatif, melalui pengelolaan manajemen pendidikan yang tepat agar nantinya bisa membetuk karakter-karakter bangsa yang cerdas dan bermoral, sesuai apa yang dicita-citakan bangsa Indonesia.

\section{Metode}

1) Mengurus permohonan izin kepada mitra/pihak yang terkait

2) Analisis Situasi untuk mengetahui lokasi penelitian dan situasi yang ada pada lokasi penelitian agar memudahkan dalam melakukan tindakan.

3) Perumusan dan Klarifikasi Permasalahan. Pelaksanaan ini dilakukan untuk mengetahui tentang permasalahan yang ada pada objek penelitian

4) Analisis Masalah. Setelah mengindentifikasi masalah, dilakukan analisis masalah guna mencari solusi dari permasalahan yang ada, dan diselesaikan berdasarkan tingkatan masalah yang ditemukan

5) Perencanaan Tindakan. Setelah menganalisis masalah, pelaksanaaan membuat rencana tindakan atau rencana kerja atau kegiatan yang akan diterapkan.

6) Inplementasi tindakan dan Memonitoringnya. Setelah menganalisissi masalah, merumuskan masalah dan membuat rencana tindakan maka yang dilakukan adalah melakukan inplementasi tentang permasalahan tersebut yaitu melakukan Pelatihan dan Pendampingan, khususnya dalam perbaikan administrasi serta pengembangan metode pembelajaran yang sesuai dengan karakter anak usia Taman Kanak-kanak dan memonitoring pelaksanaan kegiatan tersebut.

7) Evaluasi hasil tindakan untuk semua program kegiatan dan mengevaluasi sesuai target luaran.

8) Refleksi dan pengambilan keputusan untuk pengembangan selanjutnya

\section{Hasil Dan Pembahasan}

Workshop dilakukan pada tanggal 20 Agustus 2019, pada jam 8.30-17.30 wita, yang pelaksanaannya dilaksanakan di SMA MADANI, Kelurahan Paropo, Kecamatan Panakukang, Kota Makassar yang di ikuti oleh guru dan tenaga pengajar TK PKK Paropo, serta mahasiswa yang magang ditempat tersebut. Peserta workshop berjumlah 15 orang. Pembawa materi yaitu Assesor dari PAUD.

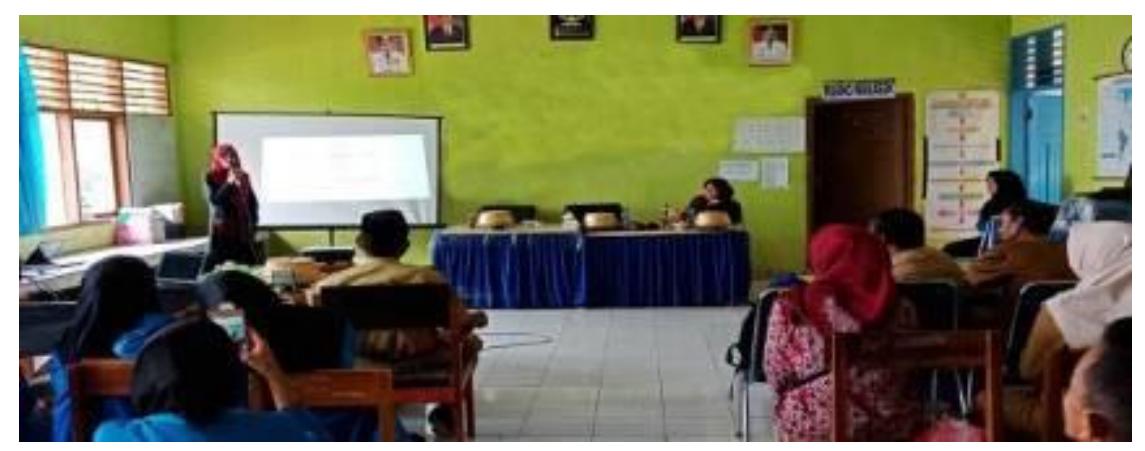

Gambar 1: Tim Memberikan Materi dalam Pelatihan Iptek

Pada tahap pelatihan dan pendampingan ini tim peneliti pertama-tama memberikan materi kepada peserta pelatihan tentang:

1. Pentingnya Pengelolaan Manajemen dan Administrasi yang baik 
Pentingnya tatakelolah manajemen dan administrasi pendidikan dikelolah dengan baik karena salah satu unsur penting dalam sebuah organisasi adalah manajemen, karena dengan adanya manajemen segala program kegiatan organisasi akan berjalan lebih baik. Hal ini juga berlaku dalam organisasi pendidikan, setiap kegiatan dalam pendidikan hendaklah diatur dengan sebuah manajemen yang baik, mulai dari perencanaan, proses, bahkan evaluasinya untuk mencapai tujuan yang diinginkan. Dengan manajemen yang baik, semua perangkat pendidikan akan dapat bersinergi dengan baik sehingga kegiatan yang diselenggarakan dapat berjalan dengan baik pula. Konsep dan prinsip-prinsip manajemen yang diterapkan dengan baik dan benar akan berdampak pada efektifitas pelaksanaan program, meningkatkan kualitas, dan produktivitas pendidikan yang pada akhirnya akan menjadikan lembaga tersebut bermutu. Pengelolaan Manajemen dalam pelaksanaan program pendidikan bukanlah tujuan, melainkan sebuah alat atau metode untuk mencapai mutu dan meningkatkan performance yang diharapkan.

\section{Memberikan Pelatihan Pembelajaran yang menarik.}

Pemateri memaparkan bagaimana mempersiapkan anak didik sebelum proses pembelajaran dimulai, seperti media pembelajarannya. Metode pembelajaran yang menarik siswa dengan menampilkan berbagai variasi media pembelajaran dan diharapkan peserta didik tidak bosan selama proses pembelajaran berlangsung, dan lebih kreatif dalam menciptakan suasana yang menyenangkan pada saat proses pembelajaran berlangsung, misalnya pada saat bermain sambil bernyanyi, guru dapat menampilkan gambar lewat video, gambar, foto yang berkenaan dengan materi serta dengan tujuan anak bisa melakukan aktivitas yang mempraktekkan kemampuan dan keterampilan dalam kegiatan tersebut, serta anak-anak lebih terarah dan merasakan ketertarikan belajar mandiri.

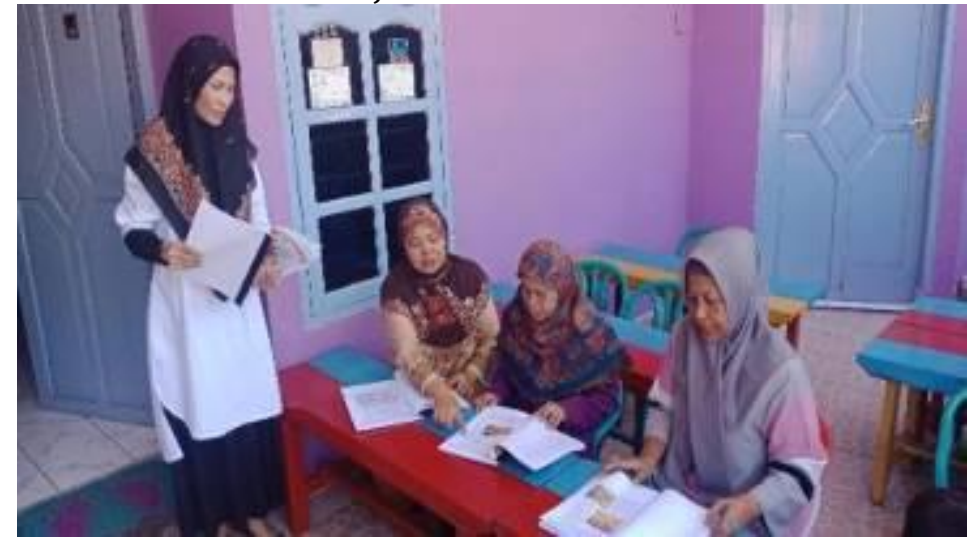

Gambar 2: Pemateri dan Peserta Workshop Mendesain Media Pembelajaran

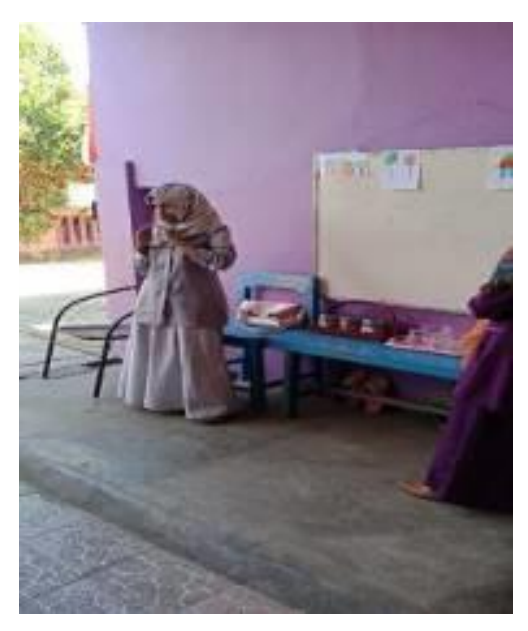

Gambar 3: Pemateri memberikan contoh metode pengajaran melaui gambar

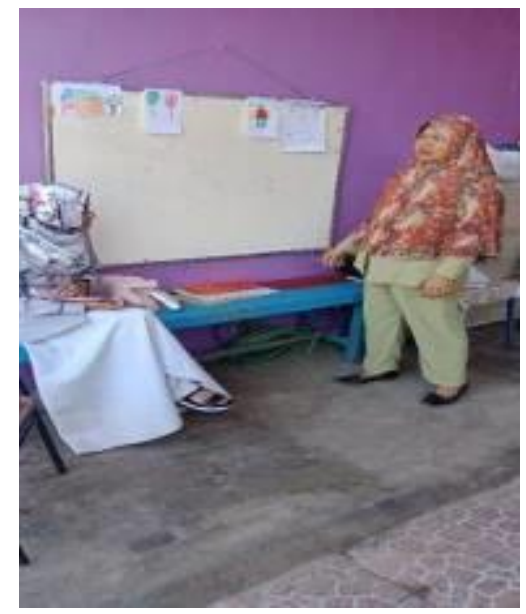

Gambar 4: Guru mempraktekkan metode pengajaran melalui gambar yang didesain pada saat pendampingan 
80| Celebes Abdimas: Jurnal Pengabdian Kepada Masyarakat

Pada pelatihan ini pemateri memaparkan beberapa cara dalam menginplementasikan penggunaan bermain sebagai media pembelajaran anak

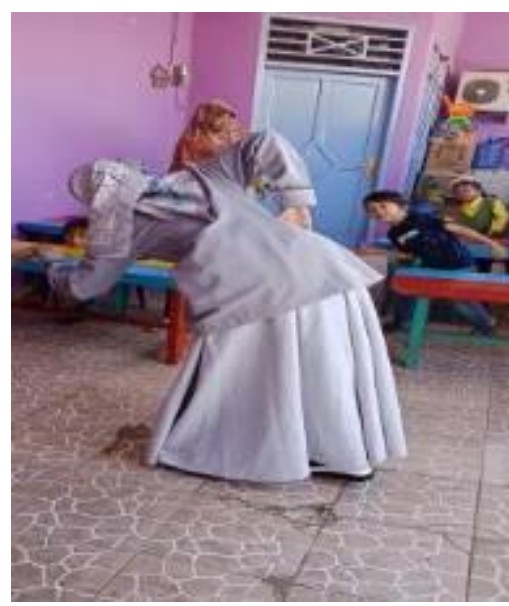

Gambar 5: Pemateri memberikan contoh metode pembelajaran belajar sambil bermain

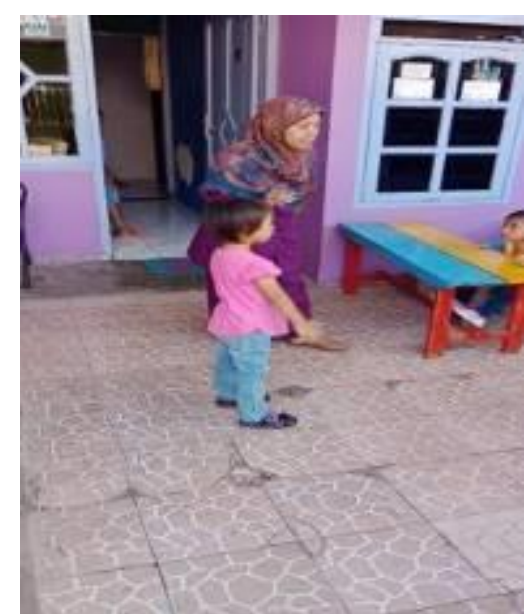

Gambar 6: Murid mempraktekkan belajar sambil bermain
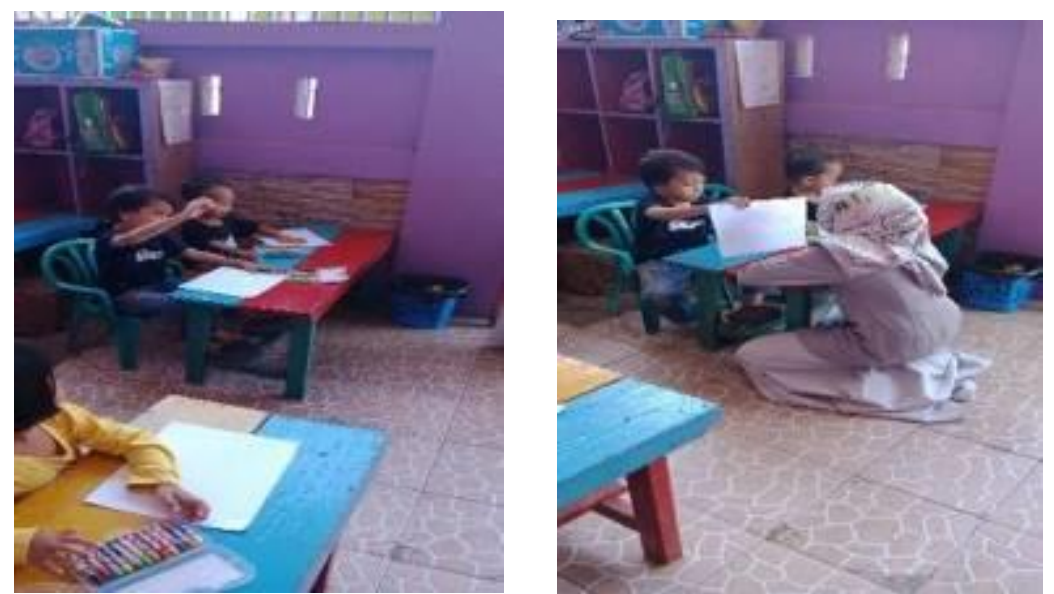

Gambar 8: Pemateri memberikan salah satu contoh Pembelajaran Berbasis Perkembangan Anak

Pada pelatihan ini pemateri memaparkan beberapa manfaat bermain sambil belajar.

1) Bermain dapat mengembangkan otot-otot di saat anak terlibat dalam aktivitas-aktivitas yang menuntut pikirannya

2) Bermain dapat mengembangkan keterampilan intelektual disaat anak terlibat dalam aktivitas-aktivitas yang menuntut pikirannya

3) Bermain dapat mengembangkan ketrampilan sosial di saat sejumlah anak terlibat aktif dalam suatu interaksi dengan orang lain

4) Bermain dapat mengemangkan aspek emosi bodi saat anak belajar mengendalikan emosinya

Peran pendidik sangatlah berpengaruh sebagai fasilitator yang penuh perhatian terhadap aktivitas-aktivitas yang dilakukan anak untuk menfasilitasi aktivitas bermain anak. Para pendidik perlu melakukan aktifitas sebagai berikut:

1) Menyediakan dan mendesain lingkungan dan perlengkapan bermain yang kaya dan aman.

2) Menyediakan waktu atau mengatur jadwal untuk aktivitas bermain yang fleksibel dan sesuai dengan kebutuhan.

3) Mengamati aktivitas anak saat bermain. 
4) Memberikan petunjuk yang diperlukan khususnya untuk melakukan suatu permainan.

5) Menciptakan suasana yang kondusif untuk bermain.

Hasil workshop ini sangat bermanfaat bagi sekolah karena proses mengajar akan lebih menarik dan tidak monoton dengan menggunakan iptek pada saat proses pembelajaran, disamping itu dengan adanya pelatihan pengembangan media pembelajaran ini akan menambah keterampilan guru dalam menyiapkan media atau alat peraga pada saat pembelajaran berlangsung.

\section{Membentuk Membentuk MGMP yaitu perkumpulan untuk guru-guru PAUD guna mempermudah informasi pelatihan-pelatihan seperti workshop dll.}

\section{Simpulan Dan Saran}

Terselenggaranya program PKM Pengabdian Masyarakat, iptek bagi TK PKK Paropo sebagai upaya meningkatkan keterampilan guru-guru yang ada di TK PKK Paropo dalam pengelolaan manajemen pendidikan dan pembelajarannya program tersebut terlaksana melalui dari beberapa rangkaian kegiatan maupun persiapan yang bertujuan untuk mengoptimalkan kegiatan tersebut. Guru sebagai agen pembelajaran perlu mengusai dan menerapkan teknologi informasi dalam pembelajaran dan untuk meningkatkan kemapuan penggunaan iptek bagi guruguru untuk kegiatan pembelajaran, serta adanya penyedia media yang menunjang proses belajar mendorong anak untuk lebih termotivasi untuk belajar serta anak-anak tidak mudah jenuh dalam menerima materi dari gurunya. Selain itu untuk berkelanjutan program ini, maka dibentuklah sebuah komunita MGMP Yaitu perkumpulan untuk guru-guru PAUD guna untuk mempermudah memperoleh informasi pelatihan-pelatihan, seperti workshop dan lain-lain. Adanya komunitas ini dapat mewadahi dan mempermudah untuk mendapatkan informasi agar tidak ketinggalan guna untuk kepentingan PAUD berkemajuan. Adapun saran dalam penelitian ini ialah : Untuk Sekolah; Bagi lembaga TK khususnya disarankan untuk meningkatkan kualitas TK dengan memberi kesempatan kepada para pendidiknya melakukan penelitian lebih lanjut, khususnya Penelitian Tindakan Kelas untuk meningkatkan perkembangan anak sebagai dasar pendidikan anak yang akan berguna untuk masa depannya. Sehingga TK semakin dipercaya masyarakat dapat meningkatkan perkembangan anak dari berbagai aspek perkembangan khususnya perkembangan keterampilan berbicara. Untuk Guru Guru; Hendaknya dalam pelaksanaan pembelajaran sebaiknya menggunakan berbagai metode-metode yang bervariasi agar anak tidak mudah jenuh dalam belajar. Untuk Pemerintah; Hendaknya pemerintah memberikan perhatian terhadap PAUD terutama sarana dan prasaranya. Guna menunjang proses belajar mengajar guru.

\section{Daftar Rujukan}

Aisyah, S., dkk. (2007). Perkembangan Dan Konsep Dasar Perkembangan Anak Usia Dini. Jakarta: Universitas Terbuka

Baharuddin., \& Wahyuni, E.N. (2007). Teori Belajar Dan PErkembangan. Jogjakarta: Ar-Ruzz Media

Conny, S. (2002). Belajar dan Pembelajaran dalam Taraf Usia Dini. Jakarta: PT Ikrar Mandiri Abadi.

Masitoh, dkk. (2005). Strategi Pembelajaran TK Jakarta. Jakarta: Universitas Terbuka

Nurani, S.Y. (2011). Konsep Dasar Pendidikan Anak Usia Dini. Jakarta: PT Indeks.

Sofia, H. (2005). Perkembangan Belajar Pada Anak Usia Dini. Jakarta: Departemen Pendidikan Nasional 
82| Celebes Abdimas: Jurnal Pengabdian Kepada Masyarakat

Sagala, S. (2003). Konsep dan Makna Pembelajaran. Bandung: Alfabeta 76.

Sugihartono, dkk. (2007). Psikologi Pendidikan. Yogyakarta: UNY Press.

Sujiono, Y.N. (2009). Konsep Dasar Pendidikan Anak Usia Dini, Jakarta: Indeks

Suyanto. (2005). Konsep Dasar Anak Usia Dini. Jakarta: Departemen Pendidikan Nasional.

Trianto. (2011). Mendesaian Model Pembelajaran Inovatif Progresif, Edisi Ke-4. Jakarta: Kencana.

Trianto. (2011). Model Pembelajaran Terpadu Konsep, Strategi Dan Implementasinya Dalam Kurikulum Tingkat Satuan Pendidikan (KTSP). Jakarta: Bumi Aksara. 